\title{
The Usefulness of Adopting the Last Planner System in the Construction Process of Addis Ababa Road Projects
}

\author{
Zenawi Mehari Limenih $\mathbb{D D}^{1,2}$ Belachew Asteray Demisse $\mathbb{D i}^{2}{ }^{2}$ and Abenezer Tariku Haile ${ }^{2}$ \\ ${ }^{1}$ Department of Construction Technology and Management, Institute of Technology, University of Gondar, Gondar, Ethiopia \\ ${ }^{2}$ Department of Civil Engineering, College of Architecture and Civil Engineering, Construction Quality \& Technology Center \\ of Excellence, Addis Ababa Science and Technology University, Addis Ababa, Ethiopia
}

Correspondence should be addressed to Zenawi Mehari Limenih; zenawi.meehari@aastu.edu.et

Received 22 November 2021; Revised 22 January 2022; Accepted 31 January 2022; Published 26 February 2022

Academic Editor: Nicola Baldo

Copyright (C) 2022 Zenawi Mehari Limenih et al. This is an open access article distributed under the Creative Commons Attribution License, which permits unrestricted use, distribution, and reproduction in any medium, provided the original work is properly cited.

\begin{abstract}
Addis Ababa road construction projects fail to be executed on time, within the allocated budget, and with the desired quality. To solve this problem, a new management concept is introduced, namely, lean construction. It is known to increase productivity and minimize waste. And, to realize this solution, last planner system (LPS) is used; it is a tool of lean construction and it involves a person or group of people with the task to control the production unit. The objectives of this study are to examine the current construction process management practice in Addis Ababa city road construction projects, to identify and prioritize the expected barriers of the last planner system implementation in Addis Ababa road construction projects using the super decision model, to identify and prioritize last planner system implementation benefits to Addis Ababa road construction projects using the super decision model, and to develop a conceptual framework for the last planner system implementation to enhance the current construction management system in Addis Ababa city road construction projects. To address the problems, questioners, observations, interviews, focus group discussions, and recently published journals were employed as qualitative and quantitative data collection tools and analyzed using statistical package for the social science version 26 and super decision model version 3.2. The finding shows that the construction management process adopted in all three sites is more or less similar, as they use a push planning system and critical path method to determine the duration following the master schedule but have no weekly work plan and lookahead schedule to forecast the coming week's duty; also, they use a push planning system, for materials. The LPS implementation expected barriers are also ranked from one to five: Labor related, internal working environment related, stakeholders related, exogenous related, and material related expected barriers, respectively. The last planner system has many benefits as agreed by different scholar. Time-related, cost-related, claim-related, and quality-related benefits are the main benefits obtained through the LPS implementation, and it is possible to conclude that LPS is useful for road construction management process. Moreover, the LPS implementation conceptual framework was also developed based on the last planner system principles.
\end{abstract}

\section{Introduction}

Road transportation is a crucial component of the economic and social development process, often absorbing a high proportion of the national budget. Most, if not all, business economies, personal economies, and public economies are the result of this transportation system. The road transport system of a developed or developing country represents a major part of that country's infrastructure significance both in terms of investment made in creating the highway network and its effect on the country's economic development [1].
Construction industry is the true power of the national economy through which the total of physical development is attained. It is an energetic component of a country's economy and has a significant effect on other industry sectors' efficiency and productivity. It is not possible to think of all-embracing investments like agriculture, manufacturing, fishery, etc., without road construction facilities [2].

In Ethiopia, like other developing countries, the road construction industry is facing productivity performance challenges in executing construction projects. Especially, asphalt road projects are characterized by their low performance, inadequate capital base, limited material and 
equipment resources, lack of skilled laborers and managers, less introduction of new technologies, and limited participation of the private sector. By considering the situation, the adoption of a new way of thinking can be the solution for problems seen in the road construction industry. Evaluating the conditions and the environment of the construction industry from the lean concept perspective will be the prerequisite for implementing this new management concept. Lean thinking is a new way to manage construction. Initially invented in manufacturing, the goals demand a new way to coordinate action, one that applies to industries far removed from manufacturing. Implementation requires action to be shaped by a deeper understanding of the goals and techniques. Lean construction is known to reduce costs, improve profit or increase competitiveness, increase business opportunity and customer base, improve health and safety, improve quality, yield higher employee salaries, shorten production timescales, and increase customer satisfaction. With little attention on research of lean construction in Ethiopia, it remains a problem of nonstandardization in waste elimination strategies, thereby sub-optimizing waste management in Ethiopia road construction projects. In general, lean construction tools are intended to improve the delivery systems and processes by minimizing wastes, increasing productivity, and health and safety, and overall, achieving client's requirements [3]. The last planner system is one tool of lean construction, where it involves a person or group of people with the task to control production unit. They are responsible for necessitating control of workflow, verifying supply stream, design, and installation in all the production units. Last planner system (LPS) is known to be the most developed practical use of Lean Construction. It focuses on minimizing the negative impacts of variability, uncertainties, buffers, making projects more predictable, creating reliable work plans, and convalescing collaborative planning. The lower performance of road construction projects is one of the basic problems which have a direct impact on the cost, time, and quality of the final product in the construction industry. This study aims to assess the usefulness of the Last Planner System implementation to advance the current construction management system in Addis Ababa Road projects.

Almost $80 \%$ of the road construction projects were completed beyond their planned completion time out of all the asphalt road construction projects that were completed from 2000 to $2005 \mathrm{Ec}$, Therefore, the researcher concluded that time overrun for asphalt road construction projects in Addis Ababa city administration is common and the root cause of this problem is the lower performance of the projects [4]. So, the decline of productivity in Addis Ababa city road construction projects is one of the greatest and most severe problems that the road construction project faces.

The general objective of this study is to assess the usefulness of the last planner system implementation to advance the current construction process management system in Addis Ababa city road projects. The outcome of this research provides a knowledge base for companies intending to implement lean construction tools like the last planner system. It would also allow companies to evaluate the strengths and weaknesses of their last planner system implementation processes based on the impact assessment results and also the company can easily measure the performance of the labor using percent plan completed (PPC). Also, the research provides a benefit to the road construction industry as it minimizes waste and increases productivity.

After studies by Professors Glenn Ballard and Greg Howell of the University of California at Berkeley in the 1990s, and their knowledge of Professor Lauri Koskela of the University of Helsinki in Finland, the Last Planner system was born. These works were formalized in scientific articles within the Lean Construction Institute, which they cofounded [5].

Last Planner System is a planning, monitoring, and controlling system used to achieve Lean Construction targets by reducing wastes, increasing productivity, and improving workflow reliability [6].

There are many benefits of implementing last planner system in road construction projects. Some of these are: reduction of variability, improvement in team motivation, empowerment of the project team, early participation of stakeholders, reduction of equipment usage, risks reduction, better production control, safety improvement, logistic improvement, an opportunity for buildability/constructability review, early identification of key barriers, improvement of quality, re-work reduction, and more efficiency in the construction process [7].

In LPS, control is handed over to comparatively lower ranks on-site rather than to the higher ranks in the hierarchy [8].

\section{Literature Review}

2.1. Road Construction Project. Road construction projects are the means through which development strategies are achieved. Development strategies which are fulfilled through successful road construction projects intend to improve the accessibility of rural area; lower costs associated with transport maintenance open more areas for development activities. Road projects, involving large amount of capital, also contribute to the total economy through job creation and result in a ripple effect to other business activities.

2.2. Road Construction in Addis Ababa. Addis Ababa road network plays a great role in the economy of the city and country. Road constructions is expected to complete on time and within the estimated budget and open for traffic, but all of the road projects are always faced to time overrun and over budget.

Once the major causes have been identified, remedies must be provided to finish the projects on schedule and within budget [2]. It is well-known that most road construction projects in Ethiopia and Addis Ababa city are exposed to time and cost overrun or both. It becomes difficult to complete road projects in the allocated cost and time [4]. 
2.3. Performance of Addis Ababa City Road Projects. The important measures necessary to be included in the road construction sector beyond the widely implemented performance measures (time, cost, quality, safety, productivity and profitability) were found to be technology adaptability, effectiveness of material management, and designer and supervisor performances. The performance measurement methods, traditional financial accounting, and balanced score card were found to be the highest Practiced Performance Methods.

Existing performance problems can also serve as a feedback tool for stakeholders' performance in project and organizational level. It can also use to develop issue-based strategy and project and organization driver measures $[9,10]$.

To execute projects more efficiently within stipulated budgets and time and per quality specifications, the study recommends AACRA to provide pieces of training on financial management. A project plan should be developed by the competent project manager and be discussed with all stakeholders before the final draft is completed and implemented, introducing new management concepts, and improving laborer productivity. This will reduce the many change orders during the construction phase that normally results in high-cost overruns. To implement the currently available technologies regarding equipment, team up with all the stakeholders involved in road projects so that they can take over the management and aid in running the projects, and practitioners can devote more effort and resources towards making their organization more team and empowerment oriented [9].

2.4. Last Planner System. The Last Planner system owes its origin to the studies by Professors Glenn Ballard and Greg Howell of the University of California at Berkeley, United States, in the 90s, and their knowledge of Professor Lauri Koskela, of the University of Helsinki, Finland. These works were formalized in scientific articles within the Lean Construction Institute, which they founded together [5].

In a traditional project management system, it talks about what should be done according to the master plan. In 2000, Ballade looked forward to a schedule that involves the following. I. Identify the Work Packages that can be completed in the following work period. II. Consulting with stakeholders to complete the work within the time constraint so that the procurement of materials and equipment will be assigned for the task in the particular week. III. Identify the work that cannot be completed for the upcoming week as required. IV. Create a set of activities that are going to be completed before delivery of the assigned work. V. When the look ahead to work for the following 5 to 10 weeks is implemented in the Last Planner System, it has an influence based on the type of project [11].

Last planner system is a holistic system, which involves the planning team to prepare a plan for the work that needs to be performed in the forthcoming weeks. It has five major parts, namely, Master planning, phase planning, make-ready planning, weekly work, and planning learning. The planning team should be ready with the abovementioned plan/ schedule so that the possible hindrance can be identified, and proper mitigation measures can be taken to perform the work seamlessly, thereby increasing the value of the project. The LPS is also called Pull planning [12].

2.5. Barriers of LPS Implementation. This shows the hindering factors for fully adopting LPS in the construction industry of different countries. There is a lack of communication and information in Egyptian sites. In Egyptian Projects, the time spent on planning issues is seen as a waste of time, and there is resistance to change and adaptation to new culture, lack of commitment from different stakeholders, and time schedules are not met [13].

2.6. Benefits of LPS Implementation. There are many benefits of implementing the last planner system in road construction projects. Some of these are reduction of variability, improvement in team motivation, empowerment of the project team, early participation of stakeholders, reduction of equipment usage, risks reduction, better production control, safety improvement, logistic improvement, an opportunity for buildability/constructability review, early identification of key barriers, improvement of quality, rework reduction, and more efficiency in the construction process [7].

One of the most commonly used tools of lean is the Last Planner System (LPS) which achieves goals through the social process of collaboration. It is a short-term project planning system to produce predictable uninterrupted workflow by creating a set of commitments that coordinates the actions of all stakeholders. LPS is a bottom-up approach whereas traditional project management uses a top-down approach. In LPS, control is handed over to comparatively lower ranks on-site rather than to the higher ranks in the hierarchy [8].

\section{Materials and Methods}

The study area of this research is at Addis Ababa, the capital city of Ethiopia. Addis Ababa was firstly chosen by Empress Taytu Betul and the city was founded in 1886 by Emperor Menelik II. It is located on the coordinate of $9^{\circ} 1^{\prime} 48^{\prime \prime} \mathrm{N}$ $38^{\circ} 44^{\prime} 24^{\prime \prime}$ E having an elevation of $2,355 \mathrm{~m}(7,726 \mathrm{ft})$ above sea level.

Research design is the blueprint for the collection, measurement, and analysis of data. From the research approaches, namely, quantitative, qualitative, and mixed research, this research used a mixed research design to answer the research questions. Mixed method research is an approach to an inquiry involving collecting both quantitative and qualitative data, integrating the two forms of data, and using distinct designs that may involve philosophical assumptions and theoretical frameworks and hence, the researcher employed both qualitative and quantitative research approaches based on the information sought. Primary data survey design for the research was realized through questioner, self-observation, and interview. 
Secondary data were also collected from recently published journal documents. This helped to review different countries' lean construction practice, the level of the last planner system implementation, and the labor performance in Addis Ababa city road construction projects.

Based on the purpose or goal of the research, it is classified under applied type because the information gathered can be used in policy formulation (providing conceptual last planner system implementation framework), administration (construction process performance improvement), and enhancement of the understanding of the phenomenon. Based on the specific objective of this research, this paper is descriptive because it tried to describe the expected barriers that hinder the implementation and benefits of adopting the last planner system in Addis Ababa city road construction projects.

The data collection instruments that are implemented and believed to be relevant to the study considered are questioner, case studies (interview, self-observation), and focus group discussion as a primary data collection method. They are normally conducted by selecting a few best fit sites for the phenomenon under analysis. They include an interview, self-observation, questioner, and focus group discussion. Recently published journals were used as a secondary data collection method.

Finally, the results of the questionnaires are analyzed using a quantitative data analysis software known as Statistical Package for the Social Science (SPSS) version 26. Simultaneously, super decision model version 3.20 was used to decide on different last planner system implementation expected barriers and the benefits of LPS implementation.

The super decision software implements the analytical network process for decision-making with dependence and feedback, a mathematical theory for decision-making developed by Thomas L. Saaty. And, it is an extension of the Analytic Hierarchy Process (AHP) for decision-making which involves breaking down problems into their decision elements, arranging them in a hierarchical structure, making judgments on the relative importance of pairs of elements, and synthesizing the result [14].

Cronbach's alpha is a reliability test that determines whether or not replies are consistent. Cronbach's Alpha is a well-known and often used criterion for evaluating questioners' internal consistency. As per Ref. [15], Cronbach alpha values range from $0-1.0$. The result greater than 0.6 are acceptable but, it is better to be greater than 0.7.be at a minimum of 0.70 or higher although a worth from 0.60 to 0.70 is suitable.

Amongst others, the AHP has become a well-known and established method for solving complex decision settings. Pairwise comparisons were therefore generated and integrated into an AHP-based decision model [16].

\section{Results and Discussion}

4.1. Findings from the Questioner. After conducting validation of the questioners, a total of 80 questioners were distributed to the three purposively selected projects including Addis Ababa city road authority, the owner of all projects. So, to the client, a total of 25 questioners were distributed and 15 were returned, for the contractors, a total of 45 questioneers were distributed and 34 were returned back, and for consultants, a total of 10 questioners were distributed and 7 were returned. A total of 56 questioners were returned, which is $70 \%$ of the total distributed questioners, as shown in Figure 1. Out of 56 respondents, 35 (62.5\%) respondents were civil engineers, 15 (26.8\%) respondents are construction technology and management professionals, while the rest $6(10.7 \%)$ professionals were architects, and it is summarized as shown in Figure 1.

\subsection{Last Planner System Implementation Expected Barriers} (Source: Own Work, 2022). Identifying and ranking the expected last planner system implementation in Addis Ababa city road construction projects was one of my objectives and the top three expected barriers are presented under their main criteria.

Internal working environment expected barriers: lack of an adequate last planner system awareness and understanding rank the first with a mean value of 4.04. The second rank was given to the hierarchies in organizational structures/unsuitable organizational structures by having a mean value of 3.70. And, management resistance to change is the third expected barrier hindering the implementation of the last planner system in Addis Ababa Road construction projects by having a mean value of 3.61. .

Stakeholder-related barriers: centralization of the decision, avoiding making decisions, and taking responsibility from those who are not in the top management had a mean score value of 3.89 . The second rank is given to lack of communication between stakeholders with a mean score value of 3.73. Lack of involvement and transparency among stakeholders was the third expected barrier to implementing the Last planner system in Addis Ababa road projects by having a mean score of 3.48 regarding.

Material-related expected barriers: inadequate delivery and delays in materials delivery are the first barriers and have a mean value of 4.02 . The second-highest expected barrier is the high price inflation of construction materials with a mean value of 3.70. And, the third rank is given to improper material management with a mean value of 3.55.. Laborrelated barriers: unfamiliarity with or misunderstanding of last planner system concepts and implementation have the first rank with a mean value of 3.86. The second expected barrier is insufficient training for workers having a mean value of 3.70. Labor considered the last planner system is too complex were ranked thirdly with a mean value of 3.54 .

Exogenous-related barriers: the first rank on the exogenous-related expected barriers is given for lack of support from the government for technological advancements by having a mean value of 3.88. And on the second rank, we get government issues such as bureaucracy and instability with a mean value of 3.45. The third expected barrier is uncertainty in the construction process with a mean value of 3.39 .

\subsection{Modeling the LPS Implementation Expected Barriers.} The super decision model software is a simple, easy to use package for developing decision models with dependency and feedback, computing the results using the super 


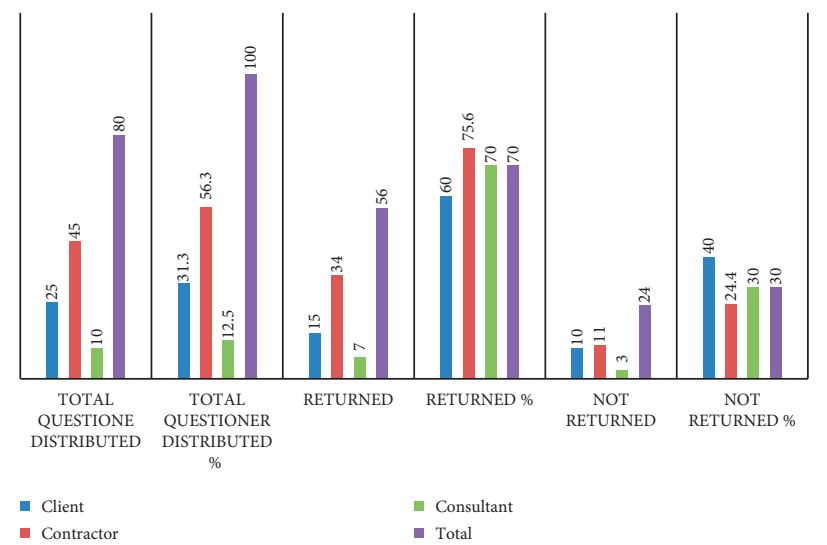

FIgURE 1: Questioners' response composition and rating. Source: own work, 2022.

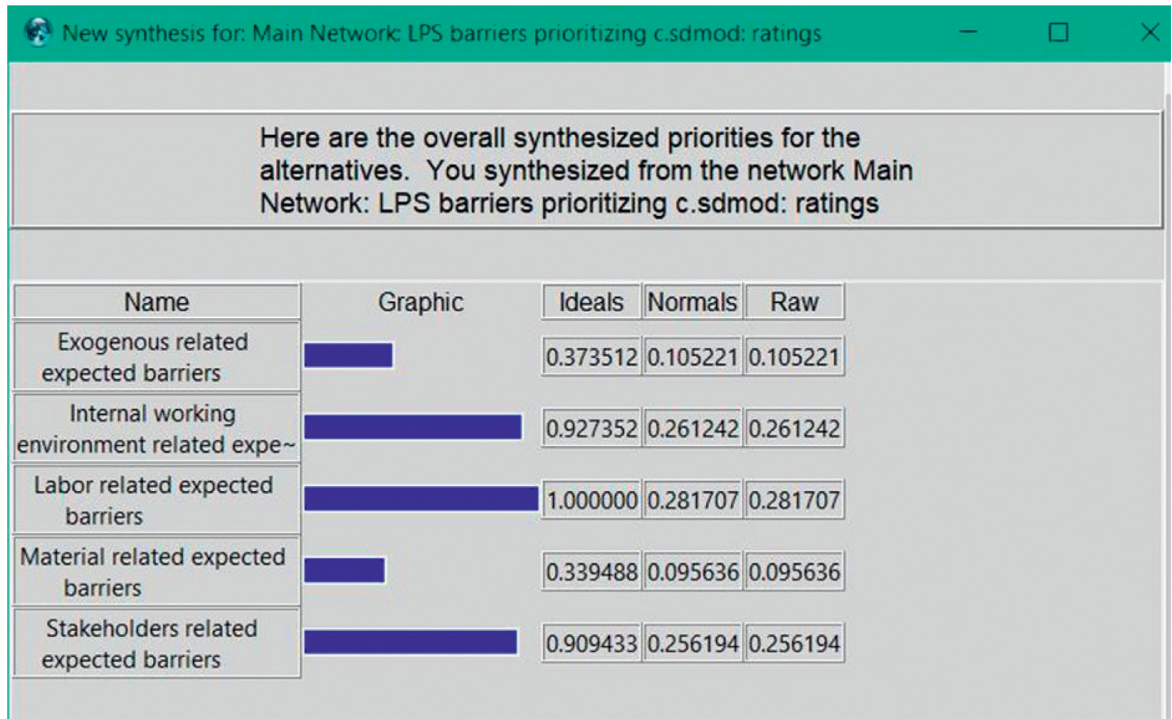

FIgURE 2: Overall LPS implementation expected barriers synthesized model. Source: own work, 2022.

matrices of the analytic network process and version 3.2.0 of the super decision model software. The expected barriers are modeled as shown in Figure 2.

A model is simply a representation of reality. To enhance our understanding of a subject matter, it is better to present the results with a model. So, the super decision model presents the result in graphical and numeric forms. The first column of the model shows the name of the five criteria, the second column presents the graphical representation of the result, the third column is about the ideal result which is the normal value divided the highest normal value, fourth column displays normals, which is the exact outcome of a criterion that is comparable to the raw criterion found in the last column.

As a result, the first rank is given for labor-related expected barriers, the second rank is for internal working environment-related barriers, the third rank is stakeholderrelated expected barriers, the fourth rank is exogenously related, and the fifth rank is for material-related expected barriers.
The results are presented in graphical and numeric forms. Finally, they were rated based on the total and ideal value, and the results are shown Figure 3 as four digits. The total and normal values are identical which shows the exact result obtained from the rating. But, the ideal result is calculated as the total or normal result of each alternative divided by the highest result among the alternatives. For example, the ideal result for the exogenous-related expected barrier is 0.3735 ; which is $0.1052 / 0.2817=0.3735$.

4.4. Benefits of LPS Implementation. Different benefits are identified from different scholars and after they are evaluated using focus group discussion, they are further analyzed using the super decision model and modeled as shown in Figure 4.

In Figure 5, the four alternatives are modeled after comparison judgments were conducted between them. The first column of the model contains names of alternatives (claim-related, cost-related, quality-related, and time- 


\section{Alternative Rankings}

\begin{tabular}{|c|c|c|c|c|c|}
\hline Graphic & Alternatives & Total & Normal & Ideal & Ranking \\
\hline & Exogenous related expected barriers & 0.1052 & 0.1052 & 0.3735 & 4 \\
\hline & Internal working environment related expected barriers & 0.2612 & 0.2612 & 0.9274 & 2 \\
\hline & Labor related expected barriers & 0.2817 & 0.2817 & 1.0000 & 1 \\
\hline & Material related expected barriers & 0.0956 & 0.0956 & 0.3395 & 5 \\
\hline & Stakeholders related expected barriers & 0.2562 & 0.2562 & 0.9094 & 3 \\
\hline
\end{tabular}

FIgURE 3: Ranking the alternatives. Source: own work, 2022.

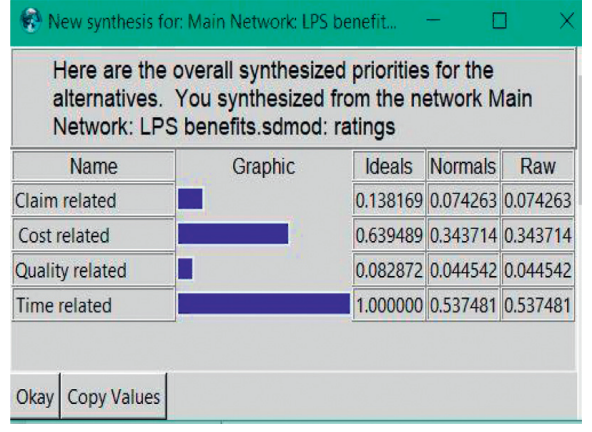

FIGURE 4: Overall synthesized priorities of LPS implementation benefit alternatives. Source: own work, 2022.

\section{Alternative Rankings}

\begin{tabular}{||c|c|c||c|c|c|c|}
\hline \hline Graphic & Alternatives & Total & Normal & Ideal & Ranking \\
\hline \hline & Claim related & 0.0743 & 0.0743 & 0.1382 & 3 \\
\hline \hline & Cost related & 0.3437 & 0.3437 & 0.6395 & 2 \\
\hline \hline & Quality related & 0.0445 & 0.0445 & 0.0829 & 4 \\
\hline \hline & Time related & 0.5375 & 0.5375 & 1.0000 & 1 \\
\hline \hline
\end{tabular}

FIGURE 5: Ranking LPS implementation benefit alternatives. Source: own work, 2022.

related) benefits. The second column displays the values of the alternatives in graphical form. The third column tells us the ideal results of the alternatives. The result of the ideals is calculated as the highest normal value divided by each value. The next two columns (normal and raw) show the exact result obtained by comparison judgment with the help of super decision model software.

The alternatives are ranked based on their total value, normal value, and ideal value. The alternative which has the highest score will be ranked at the top.

The first row contains the headings of each column. The remaining four rows are for the four different alternatives. The first columns show the results of alternatives in graphical form. The second column is a list of the alternatives. The third and fourth column displays the total and normal values, respectively, and the results are identical. And, the exact results are also available in the two columns. The fifth column contains the ideal value of alternatives which is the highest normal value divided by each of the normal values. The last column gives the rank of the alternatives based on their total, normal, and ideal values. So, based on this, time-related benefit is ranked first, the cost-related benefit is ranked second, claim-related benefits are ranked third, and the fourth benefit is quality-related benefits.
Based on the findings, we can conclude that implementation of the LPS in Addis Ababa city road construction projects gives huge benefits, and if it is implemented effectively, it is useful to enhance the construction management process as it minimizes waste and maximizes productivity, or increase value.

4.5. Findings from Self-Observation. The three different projects were chosen purposively based on the mentioned criteria in the methodology, and the observations on the selected active road projects are described. The road construction method adopted in all of the three selected sites is identical. They use the critical path method to determine the duration of the project. The detail of the projects and the problems observed in three selected different sites are summarized and presented below.

4.5.1. Construction Works of Package 20: Kera Kebt Beret-Gofa Mebrat Hail Condominium Junction Asphalt Road Project.

(i) Client: Addis Ababa City Road Authority

(ii) Consultant: Best consulting Engineers plc.

(iii) Contractor: Melcon Construction plc.

(iv) Contact amount with VAT: 214,851,545.37ETB

(v) Contract signing date: 9/4/2018

(vi) Contact period: 365 days

This road construction project should have been completed on 08/04/2019 but still now it is not completed. And, the contractor requested an extension of time more than 4 times. The contractor faces many challenges during the construction period as he stated while requesting for extension of time. And, the problems that I observe from this project are lack of well-organized material management practice, late delivery of materials, low distribution of manpower, waiting time because of lack of machinery and interference, low involvement of all stakeholders, complaints by the client on the delay of the project, and insufficient availability of health- and safety-related supports (first aid clinic, personal protective equipment, first aider, health, and safety engineer)

\subsubsection{Construction Works of Package 19: Coca-Gedame Eyesus-Mesalemiya Asphalt Road}

(i) Client: Addis Ababa City Road Authority 
(ii) Contractor: Samson Cherinet general contractor plc.

(iii) Length of road: $2.73 \mathrm{~km}$, width: $25 \mathrm{~m}$

(iv) Contact amount with VAT: 292,669,921.57 ETB

(v) Contract date: September 14/2020

(vi) Contact period: 24 months

Despite the fact that the project's completion time has not yet ended, but the schedule performance index shows that the project is behind schedule due to a variety of reasons. Problems I observed in this site are waiting time because of lack of adequate machinery, lack of laborers' motivation, lack of wellorganized material management, inefficient crew composition, site supervision problems, insufficient availability of healthand safety-related supports (first aid clinic, personal protective equipment, first aider, health, and safety engineer) and quality problems on materials.

\subsubsection{Koye Feche2 Condominium Asphalt Road Project: Lot}

3. (i) Client: Addis Ababa City Road Authority

(ii) Contractor: Ethiopian construction work corporation

(iii) Length of road: $23.2 \mathrm{~km}$, width: $7 \mathrm{~m}$

(iv) Contact amount with VAT: 555,722,466.25 ETB

(v) Contract signing date: November 12/2020

(vi) Contact period: 19 months

The remaining works cannot be completed within the remaining contract time period of nine months because the progress of the contractor is not on schedule due to many factors. In this project, I observed the following problems at the site: Inefficient use of human resources, excessive transportation time, overmanning of crews, high level of reworking time, quality problem of materials, low availability of resources, complaints by client due to behind schedule progress of the project, insufficient availability of health and safety issues (first aid clinic, personal protective equipment, first aider, health and safety engineer), and the absence of periodic site supervision. Generally, the current road construction process management system is critiqued for its poor performance of delivering projects with the expected quality, requesting time extension and price adjustment, lack of safety improvement, community dissatisfaction, and many claims and disputes among stakeholders. And, it can lead to termination of the contract.

The construction management process adopted in all three sites is more or less similar as they use the critical path method to determine the duration and they follow the master schedule but have no weekly work plan and lookahead schedule to forecast the coming week's duty. Also, they use a push planning system, especially for materials. Then, the construction management system must be enhanced by adopting new construction management systems like the last planner system to increase their performance.

4.6. Interviews' Discussion. The majority of the interviewees agreed on the need to improve the performance of the current construction process by adopting different relevant tools for road construction projects. The main thing they noticed is that we must increase team work to increase productivity and the expected output. Starting from a proper utilization of resources to minimal wastages, we need to enhance the current construction management process. But, they admit that before its adoption or introduction, there is a need to conduct research about its feasibility and compatibility to our road construction industry by different construction management professionals and universities. Also, some interviewees were opposed to the idea of introducing new construction management tools to the road construction industry because they believed that the ideas and principles of developed countries will not be compatible with our construction industry.

The benefits of the current construction management process are easily adaptable; everyone can understand it easily and it is compatible with our construction industry. The drawbacks are that it cannot minimize wastage of different resources and the process focuses on activities rather than resources like people. In most road construction projects, there is no new construction management tool or system adopted to enhance the performance. But, in some projects, they use a new management tool called kaizen. Kaizen is one tool of lean construction and it is a philosophy of continuous improvement of working practices and human resource efficiency. Kaizen believes that productivity improvement is a gradual and methodical process. Generally, kaizen has four principles, namely, visualize, measure, improve, and repeat. They declare that kaizen improves productivity, effectiveness, safety, and waste reduction.

4.7. Last Planner System Implementation Conceptual Framework. A conceptual framework is defined as a written or visual representation of an expected relationship between variables. Or it is a means (linked concepts) to help facilitate the understanding of the relationship among concepts or variables concerning the real world. It is a framework based on an existing theory in a field of inquiry that is related to and/or reflects the hypothesis of a research.

A total of 6 participants accepted the invitation, expressed their consent, and attended the focus group discussion and the remaining did not get sufficient time to attend the focus group discussion, and sent their apologies. The conceptual framework is formulated, as shown in Figure 6.

\subsubsection{Conceptual Framework Discussion}

(1) Project execution planning: this is the first stage in the last planner system in which we set project objectives and constraints, and assess the feasibility of completing the project with acceptable risk. At this stage, proceed or stop control takes the form of testing to make sure that certain preconditions are met before a task is undertaken. This type of control can be used for a specific part of the project too. After 


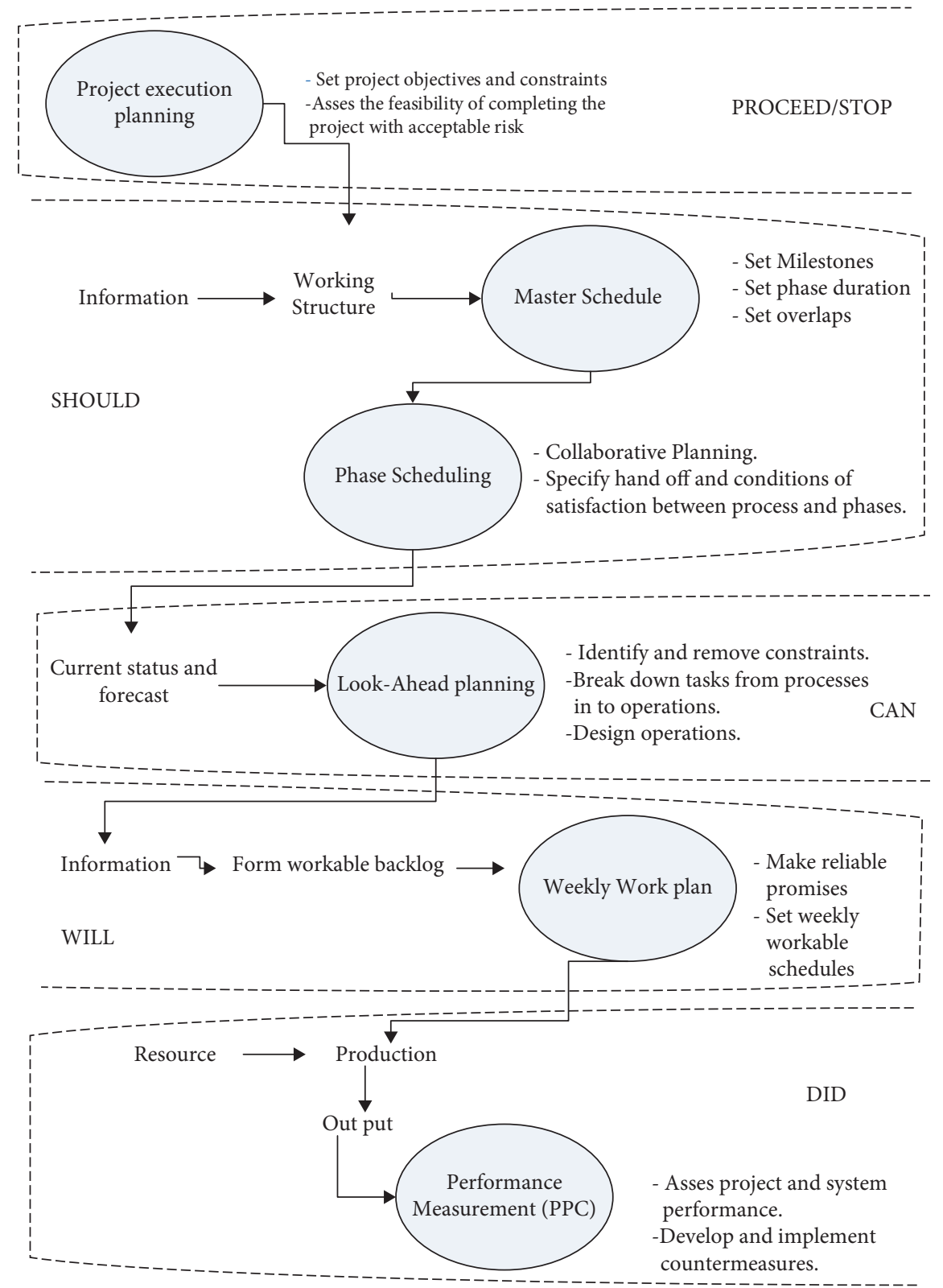

FIGURE 6: Last planner system implementation conceptual framework. Source: own work, 2022.

analysis and decision, we conclude to proceed or to stop the project.

(2) Master scheduling: before constructing a master schedule for the projects, we must gather the site conditions and other information and then we must work on the structure. After that, we construct our final master schedule. At this stage, we must identify project levels of activities for a typical road project, set milestones for the road construction projects, set phase durations, and also set overlaps. Master schedule summarizes all the works that should be done in abstract terms and it forecasts what should occur. The main purpose of master scheduling is to validate the practicality of finishing the task within the offered time, present a completing structure that can function as a main coordinating tool, and it also helps to decide at what period long lead items will be required.

(3) Phase scheduling: it is the third step that must be followed in LPS and it identifies phases for road construction projects. First, identify gross constraints that will affect the road construction project. Then perform reverse phase scheduling. Generally, in phase scheduling, there is collaborative planning, and the planner must specify handoff and conditions of satisfaction between processes and different phases. At this stage, we forecast what should occur in the future for any road construction projects. Work structuring and pull planning, and we should forecast what should be done and where; analysis is 
TABle 1: Sample look ahead planning sheet format. Source: own work, 2022.

Project:

Nature of work:

Planner:

Checked by:

Project phase:

Date

Activities

Start date

End date

Resource name

Week:

M

$\mathrm{T}$

W

$\mathrm{T}$

F

S

Total resource

TABLe 2: Weekly work plan template. Source: own work, 2022.

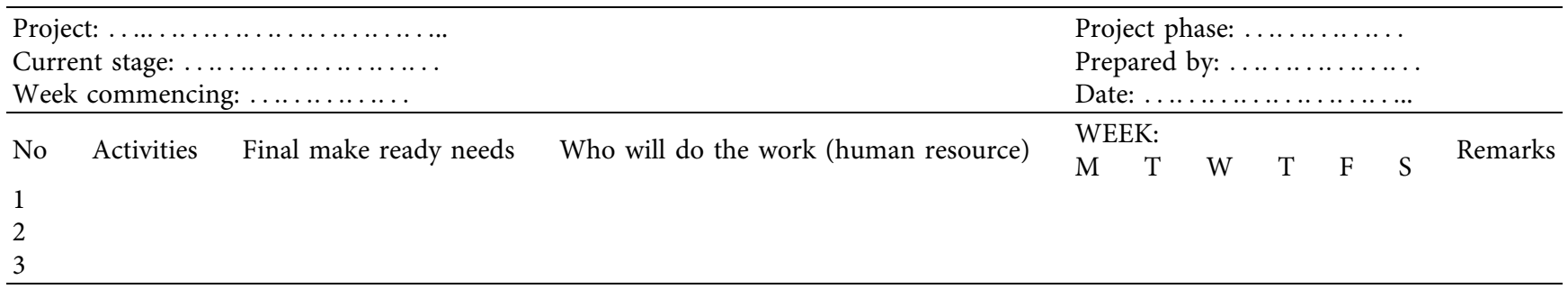

also carried out in this stage. Phase scheduling helps to outline work plan features in the best achievable details and rate for satisfying project objectives within the control of the organization time.

Look ahead planning: it generates a look ahead view of tasks for the road construction project within the next 4-6 weeks. Break down the road construction processes into operations. Perform first run studies. Identify constraints for screening and removal. must be carried out. Assign responsibilities and allocate resources for each operation or task. Based on the current status of the project, we can forecast for the future and we can see what can occur. The analysis of constraints is done by examining each activity that is scheduled to start within the next 4-6 weeks. Six weeks is typical, but lookahead windows could also be shorter or longer, depending on the speediness of the project and the lead times for information, materials, and services. On the other hand, since long lead items are items that cannot be pulled to a project within the lookahead window, extending that window offers the likelihood of greater control over workflow. On the other hand, attempting to pull too far in advance can affect one's ability to control workflow on-site. The rule governing constraints analysis is that no activity is to be allowed to retain its scheduled date unless the planners are confident that constraints can be removed in time. The aim of lookahead planning is, for mapping all the resources relevant to realize the project, to arrange the independent tasks together, thus the work statement is planned for the entire procedure jointly by multiple trades. Table 1 clearly shows a template for lookahead planning.

This format shows what will be done in the coming four to six months. And it helps to forecast the resources needed for each activity
(5) Weekly work plan: at this stage, constraint-free tasks are made ready for the coming week. Apply quality criteria (definition, size, sequence, soundness, and learning). Weekly meetings are conducted to evaluate the previous week's performance and to plan for the coming week. Based on the information we gather, we can form a workable backlog for the project and we can set a weekly workable schedule. And, we can forecast what will occur in the coming weeks. The purposes of the weekly work plan are to optimize the use of the construction unit's capability, recognize real actions, and check their feasibility earlier for task execution to shield construction units from ambiguity. And, the weekly work plan is clearly displayed in Table 2 .

The template shows the weekly work plan which helps to forecast the tasks and different resources needed for the coming week. It also describes the stage of the project, phases of the project, and the commencement date also stated in the space provided. Write the activities in the activity column and only tick on which date the activity must be executed. Clearly identify the needs so as to enable the planner to allocate the relevant resources for each activity and adjust all the preconditions needed to complete the task within the scheduled time.

(6) Percent plan completed (PPC): after we set the weekly work plan, we consume different resources and produce the desired output for the project. Then, the amount of percent plan completed must be calculated and tracked to know the performance of the crew. PPC measures the previous week's performance percent plan completed and identifies variance. PPC measurement helps to take immediate corrective actions for low performance scorer activities by assessing the root causes. Perform root cause analysis for incomplete tasks. We can evaluate whether the assigned body executed the task within 
TABLE 3: PPC observation form. Source: own work, 2022.

\begin{tabular}{lllll}
\hline \multirow{2}{*}{ No } & Task ID & Week: & Completed planned tasks & Remarks \\
& & Planned activities & Yes & No \\
\hline
\end{tabular}

TABLE 4: Reason for incomplete tasks sample form. Source: own work, 2022.

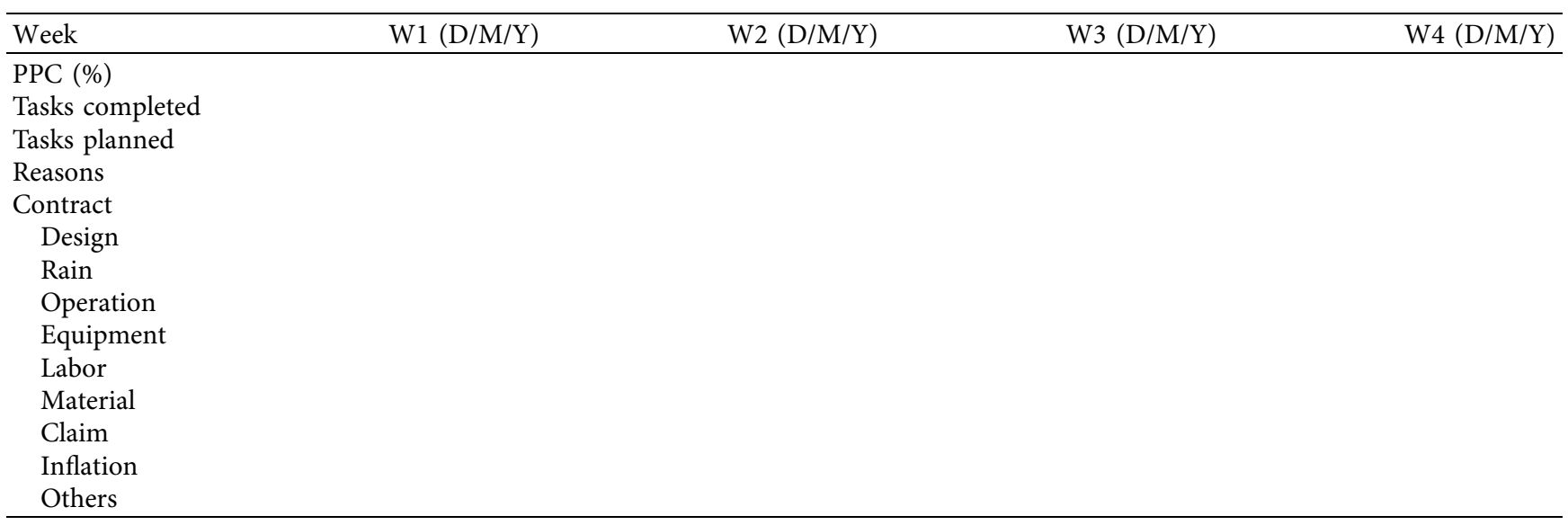

the allocated time and resource. Finally, take preventive measures to avoid low PPC.

$$
\mathrm{PPC}=\frac{\text { Work done }}{\text { Work completed }} * 100 \%
$$

Equation (1) is the PPC formula.

To overview whether the weekly work plan is executed or not, Table 3 format is very relevant. It assesses whether the activities are completed as per the schedule or not. If the activities were not completed as per the schedule, we can write the reasons on the remark column.

In Table 4, the reasons for incomplete tasks were analyzed and the problems were overcome. So, we can write the total percentage of the week's performance using equation (1) to approve if the tasks were completed or not, list the reasons, and assign which problem is faced in which week.

\section{Conclusions}

The main aim of this research was to assess the usefulness of the Last Planner System implementation to advance the current construction process management system in Addis Ababa city road projects. To achieve this objective, questioners, observations, interviews, literature reviews, and focus group discussions were employed as primary and secondary data collection instruments. The information's gathered has been analyzed with the help of different software, discussed, and presented in the previous chapter. From this study, the following conclusions were drawn: The construction management process adopted in all three sites are more or less similar; they use the critical path method to determine the duration and they follow the master schedule but have no weekly work plan and look ahead schedule to forecast the coming week's duty. Also, they use a push planning system, especially for materials. The benefit of the current construction management system is easily adaptable by different professionals and less costly. But, the current construction management system fails to minimize wastage. Then, the construction management system must be enhanced by adopting new construction management systems like the last planner system to increase the performance of road construction projects.

It is well-known that there are hindrances when new systems are adopted in the area and last planner system implementations have also many expected barriers. A total of 38 expected barriers of last planner system implementation were identified and grouped into five categories as labor-related, internal working environment-related, stakeholders-related, exogenous-related, and material-related expected barriers. The top three expected internal working environment-related barriers are lack of adequate LPS awareness and understanding, hierarchies in organizational structure, and management resistance to change. Centralization of the decision, avoiding making of decisions, taking responsibility from those who are not in the top management, lack of communication between stakeholders, strict requirements, and approvals during contracting are the top three stakeholder-related LPS implementation expected barriers. The top three material-related LPS implementation expected barriers are inadequate delivery and delays in materials' delivery, high price inflation of construction materials, and improper material management on the site. The human resource-related factors also have 
barriers as expected, and they are the unfamiliarity with or misunderstanding of the last planner system concepts and implementation, insufficient training for workers, and the labor force considering that the last planner system is too complex. Lack of support from the government for technological advancements, government issues such as bureaucracy and instability, and uncertainty in the construction process are the top three external factors related to LPS implementation expected barriers. And, among the main criteria, the criterion that is the most influential is picked. So, labor-related expected barriers become the first with a value of 0.28183 . Internal working environment-related expected barriers become the second having a value of 0.27475 . The third rank is stakeholders-related expected barriers with a value of 0.24663 . The exogenous-related expected barrier is the fourth one which hinders the adoption of LPS having a value of 0.10584 . And, materialrelated barriers are the last expected barrier scoring 0.09095.

Implementation of the last planner system in road construction projects has many benefits as agreed by different scholars. A total of 16 benefits of the last planner system implementation were identified through an intensive literature review and were grouped into four categories as time, quality, cost, and claim-related benefits. The time-related benefits are improving site management, reduction of time duration of construction activities, and logistics improvement of materials. The quality-related benefits obtained by implementing LPS in road construction projects are enhanced quality of work, improving planning and control practice in the construction process, and a reduction in the variability of the workflow. Cost-related benefits enable an accurate prediction of resources for the work planned to be executed and cost reduction. Early identification of key barriers, minimizing uncertainty in the construction process, and reducing uncertainty are the top three claim-related benefits obtained by implementing LPS. The above main criteria are also prioritized to give ranks. So, time-related benefits are the first ranked benefit having a score of 0.47608 . Cost-related benefits are ranked second with a value of 0.24711 . The third benefit is claim-related benefit with a value of 0.20474 . And, the fourth benefit obtained when LPS is adopted in the road construction process is the improvement of the quality of works by having a value of 0.07207 . So, the implementation of the last planner system in Addis Ababa city road construction projects is useful as it minimizes waste and increases productivity.

And, the last planner implementation conceptual framework was also developed based on the last planner system principles. It is validated and presented using focus group discussion. In addition, it is expected that if it is adopted to the road construction projects in Addis Ababa using the conceptual framework as a guideline or as a benchmark, it is possible to minimize wastages in the construction projects.

\section{Data Availability}

The primary data and secondary data used to support the findings of this study are available from the corresponding author upon request.

\section{Conflicts of Interest}

The authors declare that they have no conflicts of interest.

\section{Supplementary Materials}

Three different supplementary files are attached to the space provided. All of them are converted into doc. format. The first supplementary file (namely, supp doc) contains all the questioners, interview questions, different LPS implementation templates, and the output of supper decision model results. The second supplementary file is about LPS benefits. It is in doc. format and contains the codes that the superdecision model uses as an input. And, it is the converted results of the super decision model software. The third one is about the LPS implementation expected barriers. It is in doc. format. It is also the result of the superdecision model software, and it has the codes that the super decision model software uses. It is the converted file that resulted from the super decision model software. (Supplementary Materials)

\section{References}

[1] R. Kassaye, Assessment of Cause and Impacts of Local Contractors' Time and Cost Performance in Ethiopian Roads Authority Projects, Addis Ababa University Press, Addis Ababa, Ethiopia, 2016.

[2] S. G. Tadewos and D. Patel, Factors Influencing Time and Cost Overruns in Road Construction Projects: Addis Ababa, Ethiopian Scenario: Review Paper, pp. 177-180, International Research Journal of Engineering and Technology (IRJET), 2018.

[3] R. H. Ansah, S. Sorooshian, S. Bin Mustafa, and G. Duvvuru, Lean Construction Tools, pp. 784-793, International Journal of Science and Research, 2016.

[4] S. Y. Tesfa, "Analysis of factors contributing to time overruns on road construction projects under Addis Ababa city administration," International Journal of Science and Research, vol. 5, no. 7, pp. 2181-2187, 2016.

[5] M. Á. Álvarez Pérez, M. Soler Severino, and E. Pellicer Armiñana, "An improvement in construction planning: last Planner System = Una mejora en la planificación de la construcción: el sistema del último planificador," Building \& Management, vol. 3, no. 2, p. 60, 2019.

[6] A. Elkherbawy, J. A. Lozano, G. Ramos, and J. Turmo, Comparison of Project Management and Lean Construction in a Real Road Project, University of Castilla-La Mancha, Ciudad Real, Spain, 2018.

[7] O. Sánchez, K. Castañeda, R. F. Herrera, and E. Pellicer, "Benefits of last planner ${ }^{\circledR}$ system in mitigation of delay causes in road infrastructure projects," Xi Simpósio Bras. Gestão E Econ. Da Construção, vol. 11, p. 8, 2019.

[8] B. Walia and N. M. Suri, "Implementation of last planner system and challenges encountered in an Indian residential construction project," Int. Res. J. Eng. Technol.vol. 4, no. 6, pp. 2881-2888, 2017, https://irjet.net/archives/V4/i6/IRJETV4I6710.pdf [Online]. Available.

[9] M. R. Bayu, Employees Perceived Factors Affecting the Performance of Road Projects Adminstration by addis Ababa City Road Authority: The Case of Alem Bank-Betel Road Construction Project in addis Ababa, Addis Ababa University Press, Addis Ababa, Ethiopia, 2020. 
[10] T. Ayele, "Construction Performance Measurement Practice in the Road Sector: In Case of addis Ababa City Road Authority Projects, Addis Ababa University Press, Addis Ababa, Ethiopia, 2019.

[11] A. C. Harsh Shah, K. Asnani, and R. Shah, "Last planner system," p. 33, 2019, https://www.leanconstruction.org/ [Online]. Available.

[12] S. Singh and K. Kumar, "A study of lean construction and visual management tools through cluster analysis," Ain Shams Engineering Journal, vol. 12, no. 1, pp. 1153-1162, 2021.

[13] E. Aboseif and R. Khallaf, A Framework for Last Planner System Implementation in Egypt, pp. 0-5, Future University in Egypt, Cairo, Egypt, 2017.

[14] R. Saaty, DECISION MAKING IN the Analytic Network Process (ANP) for Dependence and Feedback, vol. I, University of Pittsburgh, Pittsburgh, PA, USA, 2016.

[15] K. S. Taber, "The use of cronbach's alpha when developing and reporting research instruments in science education," Research in Science Education, vol. 48, no. 6, pp. 1273-1296, 2018.

[16] W. Ossadnik, R. Kaspar, W. Ossadnik, and R. Kaspar, "Evaluation of AHP software from a management accounting perspective," Journal of Modelling in Management, vol. 8, no. 3, pp. 305-319, 2013. 